HEAD AND NECK

\title{
Indications of cone beam CT in head and neck imaging in children
}

\author{
Indicazioni all'esecuzione di una TC cone beam del distretto testa e collo \\ nei bambini \\ U. WALLICZEK-DWORSCHAK, I. DIOGO, L. STRACK, M. MANDAPATHIL, A. TEYMOORTASH, J.A. WERNER, \\ C. GÜLDNER \\ Department of ORL, Head and Neck Surgery, UKGM, Marburg, Germany
}

\section{SUMMARY}

For imaging of bony structures, especially for the anterior and lateral skull base in ORL medicine, cone beam computed tomography (CBCT) is an increasingly used alternative to CT, with a lower exposition to plain radiography that makes its use for imaging, particularly in children, very interesting. The aim of this study was to analyse possible indications and settings for CBCT in children and compare them to those of adults. A total of 554 patients (age range 0-18 years, mean age 10.36 years), who underwent CBCT between 01/2004-06/2013 in the ENT department at the university clinic of Marburg were enrolled in this retrospective analysis to evaluate technical parameters and indications. Data on CBCT of all children were compared with previously published data collected from 1730 adults who were diagnosed with the help of CBCT in the ENT department at the university clinic of Marburg, during the years 2012-2013. The most frequent indications of CBCT in children vs. adults were in the anterior skull base region: mid-facial trauma (60.4\%) vs. chronic rhinosinusitis (54.8\%), disturbed nasal breathing (13.9\% vs. 13.0\%) and chronic rhinosinusitis (12\%) vs. mid-facial trauma (10.8\%). For the lateral skull base the main indications were cholesteatoma $(20.3 \%)$ vs. position control of cochlear implant (CI) electrode (31.2\%), chronic otorrhoea (17.5\%) vs. cholesteatoma (20.9\%), and position control of CI electrode (11.8\%) vs. chronic otitis media mesotympanalis (6.8\%). CBCT is a suitable imaging modality for bony structures in adults and children. Settings mainly depend on the region of interest. One aim should also be to reduce exposure to radiation in both adults and children.

KEY WORDS: Cone beam computed tomography $(\mathrm{CBCT}) \bullet$ Indications $\mathrm{CBCT} \bullet \mathrm{CBCT}$ dosage $\bullet$ Imaging in children $\bullet$ Imaging paranasal sinus $\bullet$ Imaging temporal bone

\section{RIASSUNTO}

La TC cone beam (CBCT) rappresenta un interessante strumento diagnostico specialmente nei bambini per lo studio del basicranio anteriore e laterale, in particolar modo per la bassa esposizione a radiazioni tipica della metodica. Lo scopo del presente studio è stato quello di individuare le potenziali indicazioni per la CBCT nei bambini e il confronto rispetto alle indicazioni nell'adulto. Sono stati analizzati un totale di 554 pazienti (range 0-18 anni, media 10.36) sottoposti a CBCT da Gennaio 2004 a Giugno 2013 presso il Dipartimento di ORL della Clinica Universitaria di Marburg, allo scopo di effettuare un analisi retrospettiva dei parametri utilizzati e delle indicazioni all'esame. I dati provenienti dai bambini sono stati inoltre confrontati con un set di dati di 1730 adulti sottoposti a diagnosi mediante CBCT presso lo stesso dipartimento e già precedentemente pubblicati. Le differenti indicazioni più frequentemente rilevate all'esecuzione dell'esame negli adulti, rispetto ai bambini hanno riguardato il basicranio anteriore, e in particolare: trauma del volto $(60.4 \%)$ vs. rinosinusite cronica (54.8\%), ostruzione respiratoria nasale (13.9\% vs. $13.0 \%)$ e rinosinusite cronica (12\%) vs. trauma del volto (10.8\%). Per quanto riguarda il basicranio laterale le indicazioni principali sono state il colesteatoma (20.3\%) vs. controllo del posizionamento dell'impianto cocleare (31.2\%), otorrea cronica (17.5\%) vs. colesteatoma (20.9\%) e il controllo del posizionamento dell'impianto cocleare (11.8\%) vs. otite media cronica mesotimpanica (6.8\%). La CBCT è una metodica efficace per lo studio delle strutture ossee nell'adulto e nei bambini. I parametri di impostazione dipendono principalmente dalla regione oggetto di studio. Uno dei principali obiettivi è ridurre l'esposizione alle radiazioni sia nei bambini che negli adulti.

PAROLE CHIAVE: Cone beam computed tomography $(C B C T) \bullet$ Indicazioni $C B C T \bullet C B C T$ dose $\bullet$ Imaging nei bambini $\bullet$ Imaging dei seni paranasali $\bullet$ Imaging dell'osso temporale

Acta Otorhinolaryngol Ital 2017;37:270-275

\section{Introduction}

For imaging in otorhinolaryngology, different modalities have been established: for example, for the representation of bony structures, computed tomography is widely accepted. The two regions in ORL where CT is mostly applied are the anterior skull base and the lateral skull base. 
The main indication for imaging in these regions is the visualisation of pathologies or anatomical variants for planning therapeutic procedures, such as an operation to minimise possible complications. In the case of imaging soft tissue, magnetic resonance imaging (MRI) or sonography is preferred. In the last few years an equivalent alternative has been found, at least for bony structures, namely cone beam computed tomography (CBCT), which, like conventional CT, is based on the application of X-rays.

Penetrating human tissue, $\mathrm{X}$-rays have an ionising effect. Modifications of human genetic material (DNA) can occur that can be carcinogenic for the affected person, or even for future generations when germ cells are affected ${ }^{1}$. However, a major part of this damage can be corrected by the endogenous defence system ${ }^{2}$. This needs to be kept in mind particularly for children, who have a longer life span compared to adults. To evaluate the radiation dose that acts on the human body, the Computed Tomography Dose Index (CTDI) is a reliable value.

CBCT offers a good spatial resolution and detailed reconstruction with a lower irradiation in comparison with $\mathrm{CT}^{3}$. Basically, the lower irradiation results in higher ratio of noise. However, in daily routine, the quality of the images is good enough for sufficient diagnostic power ${ }^{4}$. Therefore, it might be a good alternative for tomography, especially in children ${ }^{5-8}$. Another advantage is that CBCT is very fast, usually taking between 9-18 seconds, and therefore it is a good alternative for patients with lower compliance. Furthermore, it is an open device, so that for claustrophobic persons and anxious children in particular, it may be a pleasant alternative to CT.

To date, while most recent studies have looked at the differences between CT and CBCT, there is no clear statement concerning the indications of CBCT in head and neck imaging in children. Therefore, the aim of the present study is to analyse and discuss possible applications of CBCT in children and to compare these indications with those of adults in the current literature ${ }^{9}$.

\section{Materials and methods}

Within this study all data of between 01/2004-06/2013 of CBCT performed on children (age between 0 and 18 years) was retrospectively analysed. All imaging procedures were performed and indicated by the Department of Neuroradiology in accordance with the patients' clinical background, based on clinical examination. In total, 650 patients fulfilled these criteria. Of these, 96 patients were excluded because the imaging was indicated and conducted by colleagues from oro-maxillofacial surgery. Finally, a total of 554 cases were analysed.

All imaging was performed with a CBCT device 3D Accu-I-Tomo, model MCT-1, type EX-2 F17 (Morita, Kyoto, Japan). This device has a detector of $17 \mathrm{~cm}$ width and $12 \mathrm{~cm}$ height and allows Field of Views from $4 \times 4 \mathrm{~cm}$ up to $12 \times 17 \mathrm{~cm}$ without any kind of stitching. With the associated software i-Dixel for processing, analyses and archiving (i-Dixel 2.0 Morita, Kyoto, Japan), the demographic and technical information of patients and images, including weighted CTDI (CTDIw), acquisition time, rotational angle, tube current and voltage as parameters for radiation exposure and the Field of View (FOV) were collected. Furthermore, the target region (paranasal sinuses/ anterior skull base, petrous bone/ lateral skull base, other), the use of scout-imaging and the necessity of repetition were evaluated.

Based on clinical charts, indications for radiological imaging were researched and divided into relevant groups. Data were analysed using the SPSS 17.0 package (SPSS Inc., Chicago, IL, USA) regarding frequency distribution and descriptive statistics. As a comparative test, the twosided t-test with independent variables was used and a 95\% confidence interval was set. Pairwise comparisons were Bonferroni corrected whenever necessary. Statistical significance level was set at $\mathrm{p}<0.05$.

\section{Results}

A total of 554 patients were enrolled in the analysis. Mean age was $10.36 \pm 5.5$ years. The study population consisted of $37.4 \%$ females $(\mathrm{N}=206)$ and $62.6 \%$ males $(\mathrm{N}=348)$. In $61.6 \%$ of cases, imaging was performed at the anterior skull base (208 male versus 133 female), whereas in $38.3 \%$ of cases it was at the petrous bone/lateral skull base (139 male versus 73 female). In one patient ( $0.2 \%$ ) looking for a foreign body, the region of interest was the neck. The following data regarding the adjustments of the $x$ ray tube and examination parameters are summarised in Tables I and II. Regarding the rotational angle of the $\mathrm{x}$ ray tube, there were differences with regards to the target areas found: an angle of $180^{\circ}$ was mainly used for $47.8 \%$ $(\mathrm{n}=163)$ of the anterior skull base region and for just $8 \%(\mathrm{n}=17)$ of the lateral skull base, whereas a rotational angle of $360^{\circ}$ was chosen for $92 \%(n=195)$ of the lateral skull base and for $52.2 \%(\mathrm{n}=178)$ of the anterior skull base.

Analysing the data of the FOV in $95.3 \%$ of the images of the lateral skull base, a $6 \times 6 \mathrm{~cm}$ (cylindrical diameter and height) window was used, while for the anterior skull base in $45.5 \%$ a $10 \times 10 \mathrm{~cm}$ window, followed by a $6 \times 6 \mathrm{~cm}$ window $(22.8 \%)$ and a 10x14 cm window (18.2\%) were used. With respect to the tube voltage, in the total patient cohort a significant difference was found between the lateral and the anterior skull base $(82.43 \mathrm{kV}$ vs. $85.06 \mathrm{kV}, \mathrm{p}=0.000)$. Also detected was a significant positive correlation between the tube voltage and the age of the patient (lateral skull base: $\mathrm{p}=0.000$; anterior skull base $\mathrm{p}=0.000$ ). No correlation was found between sex and tube voltage $(\mathrm{p}=0.778)$.

Furthermore, significant differences regarding the tube 
Table I. Technical parameters in CBCT imaging in children 2004-2013 vs. children 2012-2013.

\begin{tabular}{lcccc} 
& Tube current $(\mathrm{mA})$ & Tube voltage (kV) & Rotation angle & CTDI (mGy) \\
Anterior skull base & 4.79 & 82.43 & $180^{\circ}-47.8 \%$ & 4.24 \\
& & & $360^{\circ}-52.2 \%$ & 6.01 \\
Lateral skull base & 6.97 & 85.06 & $180^{\circ}-8 \%$ & $360^{\circ}-92 \%$ \\
\hline
\end{tabular}

Table II. Examination specifications.

\begin{tabular}{lccccc} 
& Scout & Repetition & FOV & Additional imaging & Reason for repetition \\
Anterior skull base & $33.4 \%$ & $4.7 \%$ & $14 \times 10-18.2 \%$ & $0.3 \%(1)$ & $3 \%(10)$ - motion artefacts \\
& & & $10 \times 10-45.5 \%$ & & $1.5 \%(5)$ - incomplete FOV \\
Lateral skull base & $17 \%$ & $5.5 \%$ & $6 \times 6-95.3 \%$ & $3.8 \%(8)$ & $3.7 \%(8)-$ motion artefacts \\
& & & $8 \times 8-2.4 \%$ & & $0.9 \%(2)-$ incomplete FOV \\
\hline
\end{tabular}

current were found for the different target regions, the lateral skull base vs. anterior skull base $(6.97 \mathrm{~mA}$ vs. $4.79 \mathrm{~mA}, \mathrm{p}=0.000)$. A significant negative correlation between age and tube current was found only for the anterior skull base $(\mathrm{p}=0.000)$. No correlation was found between the tube current and sex of the patients $(\mathrm{p}=0.416$ lateral skull base, $\mathrm{p}=0.193$ anterior skull base).

For the total patient cohort, a significant difference between the CTDI necessary in the lateral skull base versus the anterior skull base was found $(6.01 \mathrm{mGy} \pm 1.26$ vs. $4.24 \mathrm{mGy} \pm 1.92, \mathrm{p}=0.000)$. A positive correlation could furthermore be detected between patient age and the CTDI for anterior skull base imaging $(\mathrm{p}=0.005)$.

During the years 2004-2013, 5.5\% of the lateral skull base imaging had to be repeated, whereas the repetition rate of anterior skull base imaging was needed in $4.7 \%$ of patients. The most common reason for repetition (in total: $66.67 \%$; lateral skull base: $80 \%$; anterior skull base: $58.82 \%$ ) was a blurred image due to non-adherence of the patient, followed by an incomplete presentation of the region of interest $(33.33 \%)$. Imaging repetition was more frequent in the age group 3-7 years (Table II).

In $1.63 \%(n=9)$ of cases additional imaging seemed to be necessary to verify the suspected diagnosis $(0.3 \%(\mathrm{n}=1)$ of all anterior skull base imaging versus $3.8 \%(n=8)$ of all lateral skull base imaging). The affected age group was mostly the group of adolescents. A retrospective analysis of the additional imaging compared to the initial CBCT imaging showed that in $66.67 \%(n=6)$ no further information could be gained, whereas in $33.3 \%(n=3)$ additional information was given or another diagnosis was made (Table II).

After analysing the primary charts, a total of 26 different indications could be detected. Looking at lateral skull base imaging, a total of 12 different indications could be identified. The most common indication of the whole study collective was epitympanic chronic otitis media $(20.3 \%)$, followed by otorrhoea of unknown origin in $17.5 \%$ and position control of cochlear implant in $11.8 \%$ (Table III). For anterior skull base imaging, 10 different indications were determined, led by suspected fractures of the mid face $(60.4 \%)$, nasal airway obstruction $(11.4 \%)$ and acute rhinosinusitis $(12 \%)$ (Table III).

\section{Discussion}

The necessity of imaging in children should take into consideration how much it is really required and which structures need to be visualised. Over the last few years the use of conventional CT in the field of imaging bony structures has found strong competition in the form of CBCT.

Offering a good spatial resolution and detailed reconstruction, CBCT has lower irradiation in comparison with CT ${ }^{8}$ which, in children in particular, is a huge advantage. As the sensitivity of cells towards ionising radiation depends on the rate of mitosis of cells, those cells with a

Table III. Indications of CBCT at the lateral and anterior skull base in paediatric group.

\begin{tabular}{|c|c|}
\hline $\begin{array}{l}\text { Anterior skull base } \\
\qquad(\mathrm{N}=341)\end{array}$ & $\begin{array}{l}\text { Lateral skull base } \\
\qquad(\mathrm{N}=212)\end{array}$ \\
\hline Mid-facial trauma (60.4\%) & Cholesteatoma (20.3\%) \\
\hline Disturbed nasal breathing (13.9\%) & Otorrhoea (17.5\%) \\
\hline Chronic rhinosinusitis (12\%) & $\begin{array}{l}\text { Cochlear implant position control } \\
(11.8 \%)\end{array}$ \\
\hline Cephalgia (5.9\%) & Conductive hearing loss (11.8\%) \\
\hline Rhinorrhoea (2.3\%) & Suspected mastoiditis (8\%) \\
\hline $\begin{array}{l}\text { Tumour of paranasal sinuses } \\
(1.8 \%)\end{array}$ & Acute otitis media (6.1\%) \\
\hline Search for focus (1.5\%) & Malformation of the ear (5.7\%) \\
\hline Dacryostenosis (0.9\%) & Sensorineural hearing loss (4.2\%) \\
\hline $\begin{array}{l}\text { Exclusion of focus at paranasal } \\
\text { sinuses }(0.6 \%)\end{array}$ & $\begin{array}{l}\text { Chronic otitis media } \\
\text { mesotympanalis (3.8\%) }\end{array}$ \\
\hline \multirow[t]{3}{*}{ Planned epithesis supply (0.6\%) } & Tumour of auditory canal (3.3\%) \\
\hline & Otalgia (2.8\%) \\
\hline & Status after ear trauma (1.9\%) \\
\hline
\end{tabular}


high rate of mitosis are more sensitive towards damage caused by ionising radiation because the mitosis growth rate of cells in children is up to 10 times higher than in adults, so their cells are also more sensitive to ionising radiation. The highest sensitivity towards ionising radiation is found in newborns and decreases with age ${ }^{10}$. Another feature in children is that the endogenous mechanisms to control damage caused by radiation is not fully mature and therefore less effective compared to adults. In addition, body proportions in children are different compared with adults - for example, bone marrow is distributed in almost all body parts more homogeneously, the greater part being located in the trunk, which is why bone marrow is especially threatened and the risk of developing leukaemia is high ${ }^{11}$. Also, the risk of developing other cancers induced by radiation over the years is higher in children because compared to adults the manifestation of longterm-effects is more probable as children potentially have a longer life span ${ }^{12}$. Therefore, it is important to strictly establish the indications for x-ray-dependent examinations in children and to minimise the radiation dose. One possible way to reduce the dose is by discussing the need for quality imaging. Bitterwolf et al. demonstrated the potential of optimising irradiation for anterior and lateral skull base examinations through discussion of the clinical need for images ${ }^{13}$.

Nevertheless, in frequent cases, an imaging of bony structures is needed to confirm a diagnosis or to plan treatment. This study focused on the evaluation of indications for CBCT in daily otolaryngology imaging in children. The most common indications in the anterior skull region in children were circumscribed mid-facial trauma (60.4\%) followed by disturbed nasal breathing (13.9\%) and chronic rhinosinusitis (12\%). In comparison, in adults the most frequent indication was chronic rhinosinusitis (54.8\%), followed by disturbed nasal breathing (13.3\%) and midfacial trauma $(10.8 \%)^{9}$. These findings correspond to a study in which it was demonstrated that $80 \%$ of all imaging of the anterior skull base is based on indications of chronic rhinosinusitis ${ }^{14} 15$ and guidelines recommend $\mathrm{CBCT}$ as an alternative to conventional CT ${ }^{16}{ }^{17}$. For the second most frequent indication, i.e. disturbed nasal breathing, the successful use of CBCT was demonstrated ${ }^{18}$ and is usually performed preoperatively to predict possible complications that might be a result of individual anatomical features. The third frequent indication of adults and most frequent in children is mid-facial trauma, which refers primarily to fractures of the nasal bone. For this indication, simultaneous fractures of the mid-face bones need to be excluded, which is why a FOV of $14 \times 10$ $\mathrm{cm}$ was still the most recommended and used window, both in children and adults in the present study ${ }^{19}$. In cases of involvement of the brain or eye, or patients with multiple trauma, CT is first line choice. Regarding imaging of the lateral skull base, the most common indication in chil- dren is suspicion of cholesteatoma (20.3\%) followed by chronic otorrhoea (17.5\%) and cochlear implant electrode position control (11.8\%). The CBCT has been shown to give an equivalent visualisation of the middle and inner ear structures compared to CT, which is why it is also recommended in guidelines for chronic otitis media 2021. However, in adults, the most frequent indication is position control after cochlear implantation (CI) (31.2\%), followed by cholesteatoma (20.9\%) and chronic otitis media mesotympanalis $(6.8 \%)$. The successful diagnostic pathway for evaluating the correct position of the CI electrode has already been demonstrated, which is why it has been established in routine diagnostics ${ }^{22-25}$. In children, this is only the third most frequent indication, which might be based on the fact that $\mathrm{CI}$ implantations are more frequent in adults than in children in our clinic, and the fact that paedoatric patients are most commonly aged about one year or younger. At this age, the CBCT available at our department (sitting position) is of no use.

Regarding technical parameters, for the imaging of the anterior skull base in children in the present study, in half of the cases $360^{\circ}$ was used and in half a $180^{\circ}$ angle was utilised. Due to the fact of twice as many images, the $360^{\circ}$ setting results in a higher-quality image and allows more precise visualisation of small structures (e.g. ossicular chain). However, it was shown that the image quality using a rotational angle of $180^{\circ}$ is also sufficient, with a $50 \%$ reduction in the radiation dose, especially in the lenses and the dosage of the parotid gland ${ }^{4}$. Furthermore, the advantage of a $180^{\circ}$ mode is the shorter examination time. The $360^{\circ}$ rotational angle was mainly used for lateral skull base imaging in the present study (for adults and children), however, it could be demonstrated that here too a rotational angle of $180^{\circ}$ is adequate for sufficient imaging quality ${ }^{13}$. In the future, a rotational angle of $180^{\circ}$ should be chosen to shorten the examination time and to reduce the radiation exposure while still achieving sufficient imaging quality.

Other parameters that can reduce the radiation dose are the tube current and/or tube voltage ${ }^{26}$ and a focus on dedicated field of views. The dosage should be chosen taking into consideration the region need to be shown. As a result of this, the lateral skull base with smaller bony structures needs a higher dose in comparison to the anterior skull base $(6.97 \mathrm{~mA}$ vs. $4.79 \mathrm{~mA}, \mathrm{p}=0.000)$. In the present study, a significant correlation between the tube current and age was also found for the anterior skull base $(p=0.000)$. This demonstrates the consequent use of dose reduction protocols with lower age. The same findings could be detected in analysis of tube voltage $(85.06 \mathrm{kV}$ vs. $82.43 \mathrm{kV} ; \mathrm{p}=0.000$ ).

In consideration of this, our standard protocols with the above mentioned machine are $90 \mathrm{kV}, 3 \mathrm{~mA}$ and $180^{\circ}$ for anterior skull base and $90 \mathrm{kV}, 8 \mathrm{~mA}$ and $180^{\circ}$ for the lateral skull base. In small or slightly small children, the tube 
current is reduced by 0.5 to $1.5 \mathrm{~mA}$. The field of view (FOV - diameter $\mathrm{x}$ height of cylinder) for the anterior skull base was most frequently $10 \times 10 \mathrm{~cm}$, followed by a $6 \times 6 \mathrm{~cm}$ window. Theoretically, fractures of the nose could be diagnosed within a FOV of $6 \times 6 \mathrm{~cm}$, the problem being that neighbouring parts of the mid-face bones cannot be evaluated sufficiently and so fractures of the mid face could be overlooked in this setting ${ }^{18}$. Therefore, in our opinion it is recommended to use at least the $10 \times 10 \mathrm{~cm}$ FOV. For the lateral skull base, a window of $6 \times 6 \mathrm{~cm}$ was mainly used. The FOV should be large enough to show the whole region of interest, but not too large, because local resolution decreases and radiation exposure increases as the size of the FOV increases ${ }^{27}$.

The decision on how to proceed in a case of bilateral ear imaging should be performed individually, taking into account the applied radiation exposure, risk of movement artefacts and need for FOV. Comparing the different FOVs used in anterior vs. lateral skull base imaging, the fact that the structures of the paranasal sinuses are larger in contrast to the ear structures should be taken into consideration, which is why a larger FOV could be chosen here.

In the present study, $5.5 \%$ of the lateral skull base imaging and $4.7 \%$ of the anterior skull base imaging had to be repeated. The most common reason for this was a blurred image as a result of motion artefacts, followed by an incomplete FOV (Table I). Particularly in the age group 3-7 years, image repetition was more frequent. In lateral skull base imaging a rotational angle of $360^{\circ}$ was frequently used, which results in a longer examination time (16.87 sec \pm 2.5 lateral skull base vs. $13.42 \mathrm{sec} \pm 4.24$ anterior skull base) and thus a higher possibility of motion artefacts because keeping still for a longer time is more difficult, especially for children. Nevertheless, in the comparable group of adults, motion artefacts were also the most common reason for image repetition in lateral skull base ${ }^{9}$. Possibilities for reducing the number of repetitions are the use of positioning aids ${ }^{28}$, reduction of examination time and detailed explanation of the importance of a steady head position.

\section{Conclusions}

CBCT is a good alternative to conventional CT as an imaging technique of bony structures in children as well as in adults. The most frequent indications for anterior skull base imaging in children are circumscribed mid-facial trauma, disturbed nasal breathing and chronic rhinosinusitis compared to lateral skull base imaging for which the most frequent indications are cholesteatoma, otorrhoea and cochlear implant position control. In case of involvement of the soft tissue (e.g. orbital/ central complications) MRI or CT should be performed. Tube adjustments mainly depend on the region of interest. One aim should be a consequent reduction of radiation exposure by using a rotational angle of $180^{\circ}$ on the back of the head.

\section{References}

1 Mathews JD, Forsythe AV, Brady Z, et al. Cancer risk in 680,000 people exposed to computed tomography scans in childhood or adolescence: data linkage study of 11 million Australians. BMJ 2013;346:f2360.

2 Lobrich M, Rief N, Kuhne M, et al. In vivo formation and repair of DNA double-strand breaks after computed tomography examinations. Proc Natl Acad Sci U S A 2005;102:8984-9.

3 Güldner C, Zimmermann AP, Diogo I, et al. Age-dependent differences of the anterior skull base. Int J Pediatr Otorhinolaryngol 2012;76:822-8.

4 Güldner C, Ningo A, Voigt J, et al. Potential of dosage reduction in cone-beam-computed tomography (CBCT) for radiological diagnostics of the paranasal sinuses. Eur Arch Otorhinolaryngol 2012;270:1307-15.

5 Penninger RT, Tavassolie TS, Carey JP. Cone-beam volumetric tomography for applications in the temporal bone. Otol Neurotol 2011;32:453-60.

6 Stratemann SA, Huang JC, Maki K, et al. Comparison of cone beam computed tomography imaging with physical measures. Dentomaxillofac Radiol 2008;37:80-93.

7 Eggers G, Muhling J, Hofele C. Clinical use of navigation based on cone-beam computer tomography in maxillofacial surgery. Br J Oral Maxillofac Surg 2009;47:450-4.

8 Eggers G, Klein J, Welzel T, et al. Geometric accuracy of digital volume tomography and conventional computed tomography. Br J Oral Maxillofac Surg 2008;46:639-44.

9 Stutzki M, Jahns E, Mandapathil MM, et al. Indications of cone beam CT in head and neck imaging. Acta Otolaryngol 2015:1-7.

10 Bahreyni Toossi MT, Malekzadeh M. Radiation dose to newborns in neonatal intensive care units. Iran $\mathrm{J}$ Radiol 2012;9:145-9.

11 Alzen G, Benz-Bohm G. Radiation protection in pediatric radiology. Dtsch Arztebl Int 2011;108:407-14.

12 Brenner D, Elliston C, Hall E, et al. Estimated risks of radiation-induced fatal cancer from pediatric CT. AJR Am J Roentgenol 2001;176:289-96.

13 Bitterwolf L, Lunzner K, Heinrichs J, et al. Dosisreduktion unter Betrachtung der erforderlichen Bildqualitat - Wie viel Dosis braucht ein Bild? Laryngorhinootologie 2013;92:332-7.

14 Dammann F. [Imaging of paranasal sinuses today]. Radiologe 2007; 47:576:578-83.

15 Dammann F, Grees H, Kösling, et al. Algorithmen für die Durchführung radiologischer Untersuchungen der KopfHals-Region. AWMF 2015;039/93.

16 Stuck BA, Bachert C, Federspil P, et al. Leitlinie "Rhinosinusitis" - Langfassung: S2-Leitlinie der Deutschen Gesellschaft fur Hals-Nasen-Ohren-Heilkunde, Kopf - und HalsChirurgie. HNO 2011;60:141-62.

17 Stuck BA, Hulse R, Barth TJ. Intraoperative cone beam computed tomography in the management of facial fractures. Int J Oral Maxillofac Surg 2012;41:1171-5.

18 Bremke M, Gedeon $\mathrm{H}$, Windfuhr JP, et al. [Nasal bone fracture: etiology, diagnostics, treatment and complications]. Laryngorhinootologie 2009;88:711-6.

19 Bremke M, Sesterhenn AM, Murthum T, et al. Digital vol- 
ume tomography (DVT) as a diagnostic modality of the anterior skull base. Acta Otolaryngol 2009;129:1106-14.

${ }^{20}$ German Society of Otorhinolaryngology HaNS. LeitlinieChronisch mesotympanale Otitis media. AWMF 2014;017-74.

21 German Society of Otorhinolaryngology HaNS. LeitlinieCholesteatom. AWMF 2014;017-06.

22 Ruivo J, Mermuys K, Bacher K et al. Cone beam computed tomography, a low-dose imaging technique in the postoperative assessment of cochlear implantation. Otol Neurotol 2009;30:299-303.

23 Aschendorff A. Imaging in cochlear implant patients. Laryngorhinootologie 2011;90(Suppl 1):S16-21.

${ }^{24}$ Aschendorff A, Kromeier J, Klenzner T, et al. Quality control after insertion of the nucleus contour and contour advance electrode in adults. Ear Hear 2007;28:75S-79S.

${ }^{25}$ Güldner C, Weiss R, Eivazi B, et al. [Intracochlear electrode position: evaluation after deep insertion using cone beam computed tomography]. HNO 2012;60:817-22.

26 Nagel HD. CT Parameters that influence the radiation dose. In: Tack D, Gevenois PA, editors. Radiation Dose from Adult and Pediatric Multidetector Computed Tomography. Berlin \& Heidelberg: Springer; 2007. pp 51-79.

27 Lofthag-Hansen S. Cone beam computed tomography radiation dose and image quality assessments. Swed Dent J Suppl 2010;209:4-55.

28 Schulze R, Heil U, Gross D, et al. Artefacts in CBCT: a review. Dentomaxillofac Radiol 2011;40:265-73.

Received: April 19, 2016- Accepted: September 21, 2016

Address for correspondence: Christian Güldner, University Hospital of Marburg, Department of ORL, Head and Neck Surgery, Baldingerstraße 35043 Marburg, Germany. Tel. +49 64215869052. Fax +49 6421 5866367. E-mail: gueldner@ staff.uni-marburg.de 